\title{
Increase the production efficiency of organization at the enterprise based on the technology of increasing the productivity and quality on the production flow of parts
}

\author{
Garina E.P. ${ }^{1}$, Garin A.P. ${ }^{2}$, Romanovskaya E.V. ${ }^{3}$, Andryashina N.S. ${ }^{4}$, Kozlova E.P. ${ }^{5}$ \\ ${ }^{1}$ Minin Nizhny Novgorod State Pedagogical University (Minin University), Nizhny Novgorod, Russian Federation, \\ e-mail: e.p.garina@mail.ru \\ ${ }^{2}$ Minin Nizhny Novgorod State Pedagogical University (Minin University), Nizhny Novgorod, Russian Federation, \\ e-mail: direktor@reklamapovolzhya.ru \\ ${ }^{3}$ Minin Nizhny Novgorod State Pedagogical University (Minin University), Nizhny Novgorod, Russian Federation, \\ e-mail: alenarom@list.ru \\ ${ }^{4}$ Minin Nizhny Novgorod State Pedagogical University, Nizhny Novgorod, Russian Federation, \\ e-mail: natali_andr@bk.ru \\ ${ }^{5}$ Minin Nizhny Novgorod State Pedagogical University, Nizhny Novgorod, Russian Federation, \\ e-mail: elka-a89@mail.ru
}

\begin{abstract}
The relevance of the paper research is due to the fact most car manufacturers suffer significant losses and reduce production because of the falling demand. Therefore the challenge of changing the production organization model, reducing costs and increasing labor productivity through the search for internal reserves rises.

The aim of the paper is to increase the production efficiency of organization at mechanical engineering enterprises.

The research conducted by the authors makes it possible to conclude in modern market conditions, the cost, price and, accordingly, the competitiveness of enterprise products are largely determined by the state of the main elements of production, as well as the efficiency of their use, that is, the level of organization of the main production processes. Consequently, the authors defined the role of improving the organization of production processes in the efficiency of industrial enterprises. As a result, continuous improvement of the main and additional processes ensures the stable and long-term competitiveness of the industrial enterprise.

The authors determined the main business unit of the enterprise, a description of the production unit activities was given, the main problems in the organization of workshop production were identified, the directions for improving the production efficiency of organization at the enterprise were determined.

During the work, theoretical and practical research methods were used, such as analysis, synthesis, generalization of experience, experimental method, quantitative and qualitative processing of results, observation, static methods.
\end{abstract}

Key words: technology, production process, efficiency, productivity, mechanical engineering.

\section{INTRODUCTION}

In the sphere of theoretical and practical work on the production organization, positive experience has been accumulated, which has been transferred in the research of scientists and entrepreneurs, such as G. Ford, F. Taylor, P. Drucker, A. Faiol, K. Adamechkin, O.I. Neporent.

The organization of production is obligatory for the effective operation of any enterprise, since it makes favorable opportunities for the high-executive work of labor collectives, the production of good quality, the full use of all the enterprise resources and the comprehensive development of the individual in the labor process [4].

The organization of production must meet the goals and objectives of the enterprise, the choice of development strategy and tactics and an effective management system.

Therefore, the organization of production consists of the integration and provision of production elements, the establishment of the necessary connections and the coherence of the participants' actions in the production process, the conditions' implementation for the realization of the common economic interests of the company, the owner of production, the team and each employee $[1,5]$.

In general, the development level of productive resources characterizes the level of efficiency of an industrial enterprise [6]. Calculation of economic efficiency criteria allows to determine efficiency level of production and economic activity of the enterprise. It makes an idea of what cost of resources the economic effect is achieved at.

Profitability calculation of various directions of the enterprise's economic activity is carried out to solve the following planning and economic problems [2, 3].

- To identify and assess the use level of individual costs and resources and to determine the cost-effectiveness of production at its various levels.

- For economic proofs and selection of optimal production and economic solutions: implementation of new equipment, technologies, development of new and 
effective directions of production organization, labor and management.

\section{RESEARCH}

"GAZ Group" is the main supplier of unique passenger commercial and medium-duty vehicles in its type for small and medium-sized businesses, various industries, utilities and agricultural enterprises.

"GAZ Group" makes competitive commercial vehicles, heavy vehicles, passenger buses, special equipment and automotive components. It provides engineering products to various sectors of the economy, social types of transportation and guarantees the safety, reliability of equipment, as well as economic benefits during its operation.

We will analyze the efficiency of the production organization of PJSC "GAZ" activities using the example of a separate business unit - the steering control and heat treatment workshop.

The workshop equipment is divided into main, additional and auxiliary [7].

The main equipment is required for thermal treatment processes. Example of equipment: furnaces, baths, installations of high frequency currents (including for heating in electrolyte and flame hardening), quench tanks and machines, equipment for cold treatment (Figure 1).

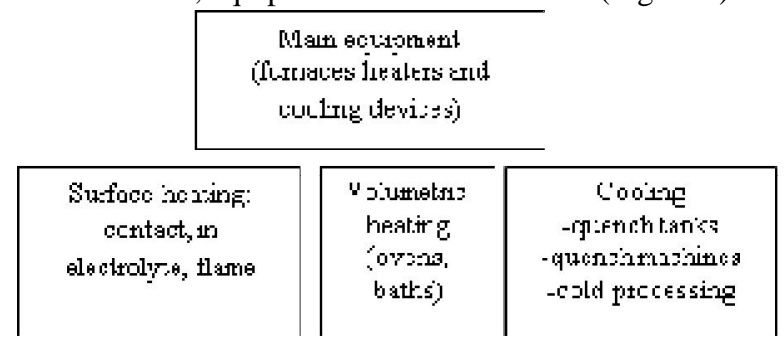

Figure 1: Main equipment of thermal workshop

Additional equipment is used to execute the operations which follow hardening and release: washing tanks and washing machines.

Auxiliary equipment consists of installations for the preparation of solid and liquid carburizers, gas atmospheres, lifting and transportation machines, blowers. For example, a carburizer is a material by which steel is cemented (carburized); the most common carburizer is a mixture of charcoal and soda, which is filled with a cemented product.

\section{RESULT AND DISCUSSION}

Let's consider the problems of the stabilizer rod assembly section.

The transverse stability stabilizer is part of the automotive suspension connecting the opposite wheels with the help of a torsion type elastic element (works for twisting) (Figure 2).

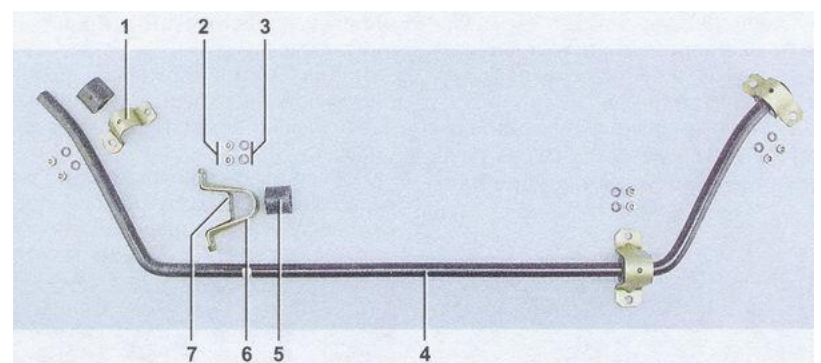

1 - sleeve clip;

2 - nut;

3 - spring washer;

4 - transverse stability stabilizer;

5 - cross-stability stabilizer bar bush;

6 - external stability bracket;

7 - internal stability bracket

Figure 2: Example of stabilizer rod

Currently, the transverse stability stabilizer is a mandatory element of various types of independent suspension of passenger cars. The stabilizer is installed on both the front and rear axles of the car, but in cars using a torsion rod as a rear suspension, the transverse stability stabilizer is not installed. Its functions are executed by the suspension itself [8].

The following problems could be distinguished among the main problems of production organization in the researched business unit:

1. high time costs of periodic mode for parts transportation from painting to work place (981second).

2. reduced quality of parts - chipping of paint coating on the surface of the rod as a result of developed logistics absence inside the workshop and among separate stages in the production chain as a whole. For example, there is a significant contamination of the working area with parts, trolleys, tables; long enough time period for movement of work in process elements in the flow (up to 5 days).

3 . long re-setting time - 36 minutes, for each modification of the stabilizer rod. Lever actuation of the press, the operator has to bend to execute pressing of the parts.

4. operator waiting for press rubber-metal joints into tip (8 $\mathrm{sec})$. In particular: uneven work of operators - from $52 \%$ to $95 \%$; large fluctuations in operators workplaces - up to $50 \%$; long time of periodic work - up to $22 \%$; large quantities of inventory in workplaces; a large number of complaints - by 3489.3 thousand rubles; underdevelopment of the production system.

Subject to the listed problems in the production organization in the researched business unit, the costs for the assembly flow of the stabilizer rod are the following: (Table 1).

Table 1: Costs of assembly flow "of stabilizer rod"

\begin{tabular}{|l|c|c|}
\hline \multicolumn{1}{|c|}{ Economic indicator } & $\begin{array}{c}\text { Measurement } \\
\text { units }\end{array}$ & $\begin{array}{c}\text { Current } \\
\text { state }\end{array}$ \\
\hline Butter И-20 & thousand rubles & 19,08 \\
\hline $\begin{array}{l}\text { Electricity consumption } \\
\text { (two pieces of } \\
\text { equipment) }\end{array}$ & thousand rubles & 20,81 \\
\hline $\begin{array}{l}\text { Maintenance of two } \\
\text { items of equipment }\end{array}$ & thousand rubles & 36,89 \\
\hline Delivery of two pieces of & thousand rubles & 0 \\
\hline
\end{tabular}




\begin{tabular}{|l|l|c|}
\hline $\begin{array}{l}\text { equipment in metal } \\
\text { recycling }\end{array}$ & & \\
\hline $\begin{array}{l}\text { Diesel fuel consumption } \\
\text { for parts transportation }\end{array}$ & thousand rubles & 21,12 \\
\hline
\end{tabular}

Equipment costs amount to 97.9 thousand rubles. Thus, it is necessary to develop measures to minimize costs.

To eliminate the problem of paint coating chips on the "stabilizer rod" parts and reduce the time for parts transportation in the perspective, it is necessary to:

1. Transfer manufacturing of parts to painting area and place assembly flow on painting expedition areas.

Initially, the assembly of the part was carried out in the flow of the machining line, which led to the transportation of components to the chips of the paint coating on the surface of the product.

2. In the future, it is necessary to develop and implement an electronic file of the production analysis sheet, which automatically calculates the time for the task production during multi-item production, to reduce the time for the supervisor to issue the task to the operator. An electronic production analysis sheet would reduce the time spent by the expert to issue a task from 34 minutes to 5 minutes. The production analysis sheet allows the expert to monitor progress during the shift. When a problem happens, the operator turns on a special signal and records the problems in the production analysis sheet.

\section{CONCLUSION}

As the research shows the final results of the project are: increased labor productivity, reduced process time, change in operator work.

Improving the efficiency of activities has a multilateral, integrated impact on the economy of the enterprise, which ensures its sustained economic growth, profitability, and, as a result, survival in acute competition in a market economy.

The practical value of the research is the possibility of using the developed recommendations to increase the efficiency of production organization in an industrial enterprise.

\section{REFERENCES}

1. Garina E.P., Garin A.P., Tsymbalov S.D., Romanovskaya E.V., Andryashina N.S. Modeling of approaches of product development and production processes: existing problems and proposed solutions // Studies in Computational Intelligence. 2019. T. 826. pp. 1115-1127.

2. Garina E.P., Kuznetsov V.P., Andryashina N.S., Romanovskaya E.V., Kuznetsova S.N. Exploring alternative strategies for managing the complexity of a product // The Future of the Global Financial System: Downfall or Harmony. "Lecture Notes in Networks and Systems" Cham, Switzerland, 2019. pp. 741-747.

3. Garina E.P., Kuznetsov V.P., Garin A.P., Romanovskaya E.V., Andryashina N.S. Increasing the complexity of the product manufacture: assessment of trends and prospects of the process // The Future of the Global Financial System: Downfall or Harmony. "Lecture Notes in Networks and Systems" Cham, Switzerland, 2019. pp. 748-756.

4. Garina E.P., Kuznetsov V.P., Romanovskaya E.V., Andryashina N.S., Efremova A.D. Research and generalization of design practice of industrial product development (by the example of domestic automotive industry) //Quality - Access to Success. 2018. T. 19. № S2. pp. 135-140.

5. Kuznetsov V.P., Kuznetsova S.N., Romanovskaya E.V., Andryashina N.S., Garina E.P. Technological renewal of industrial sectors through creation of high-tech industrial eco-clusters // Studies in Computational Intelligence. 2019. T. 826. pp. 1089-1095.

6. Kuznetsova S.N., Romanovskaya E.V., Artemyeva M.V., Andryashina N.S., Egorova A.O. Advantages of residents of industrial parks (by the example of AVTOVAZ) // Advances in Intelligent Systems and Computing. 2018. T. 622. pp. 502-509.

7. Smirnova, Z.V., Mukhina, M.V., Katkova, O.V., Gruzdeva, M.L., Chernei, O.T. Network Interaction as a Factor of Professional Qualities' Development of Service Workers // Lecture Notes in Networks and Systems, 87, pp. 698-704.

8. Yashin S.N., Koshelev E.V., Sukhanov D.A., Kuznetsov V.P., Romanovskaya E.V. Method selection of graphic-analytical justification of effective innovative projects in the industrial safety field // Studies in Computational Intelligence. 2019. T. 826. pp. 1097-1114. 